\title{
Desain dan Implementasi Kendali Cerdas untuk Robot Quadpod (Berkaki Empat) - Studi Kasus Robot Pemadam Api (RPA)
}

\author{
Muhammad Bagus Bintang Timur ${ }^{1)}$, Achmad Fanany Onnilita Gaffar ${ }^{2)}$,Agusma Wajiansyah ${ }^{3)}$ \\ 1,2,3) Jurusan Teknologi Informasi Politeknik Negeri Samarinda \\ mc.bintang@gmail.com
}

\begin{abstract}
In robot fire extinguisher not only extinguish the fire but search for space contained by fire. When a robot searches for a fire inside the room, the robot goes through the process and tries to know the surroundings in order to know the position of the robot and to know what action to take, on positioning not only knowing where the robot is but also knowing the direction of the robot. This study aims to build intelligent control based Fuzzy Logic (Logic Samar) to determine the position of robots are located when inside the arena or the environment. Fuzzy Logic Testing using Mathlab Software (software). The sensor data as a reference environment is built on Random (random). Once data is built, data is then processed using Fuzzy Logic. The result will be robot position. From that position it will be known where the robot and what decisions to take.
\end{abstract}

Keywords: Artificial Intelligent, Fuzzy Logic, Robot, Quadpod.

\begin{abstract}
Abstrak
Pada robot pemadam api tidak hanya sekedar memadamkan api melainkan mencari ruang yang terdapat api. Ketika robot mencari api yang terdapat didalam ruangan, robot melakukan proses berjalan dan berusaha mengetahui lingkungan sekitar agar dapat mengetahui posisi robot berada dan mengetahui tindakan apa yang harus diambil, pada penentuan posisi tidak hanya mengetahui dimana robot berada tapi juga mengetahui posisi arah robot. Penelitian ini bertujuan untuk membangun Kendali Cerdas berbasis Fuzzy Logic (Logika Samar) untuk menentukan posisi robot berada ketika berada didalam arena atau lingkungan sekitar. Pengujian Fuzzy Logic menggunakan Software (perangkat lunak) Mathlab. Data sensor sebagai referensi lingkungan dibangun secara Random (acak). Setelah data dibangun, data kemudian diproses menggunakan Fuzzy Logic. Hasil proses akan berupa Posisi robot. Dari posisi tersebut maka akan diketahui robot berada dimana dan keputusan apa yang harus diambil.
\end{abstract}

Kata Kunci: Kendali Cerdas, Fuzzy Logic, Robot, Quadpod.

\section{Pendahuluan}

Sebagian besar dari penelitian penelitian awal di bidang robotika modern didukung oleh kepentingan - kepentingan komersil, sasarannya secara ekonomis adalah mengembangkan robot - robot perakitan yang dapat dipergunakan di pabrik - pabrik untuk meningkatkan produktivitas dan konsistensi.Robotika merupakan disiplin ilmu yang didominasi oleh bidang - bidang keilmuan yang lebih tradisional seperti teknik mekanika (mesin) dan teknik elektro.Pengembangan perangkat - perangkat semisal penggenggam presisi tingi (Precision gripper) dan lengan yang sangat fleksibel (Highly flexible elbow) seringkali lebih diutamakan ketimbang pengembangan kecerdasan yang mendasari kemampuan perangkat - perangkat tersebut. [1]

Keuntungan robot berkaki ialah mampu bergerak di daerah yang halus atau kasar, bergelombang dan tidak rata atau datar, memanjat tangga, menghindar dan melangkah di atas halangan. Salah satu jenis robot berkaki yang paling banyak digunakan ialah robot Hexapod (berkaki enam).Hexapod memiliki banyak keuntungan di antaranya ialah Fleksibilitas dalam pola gerakan, karena robotmemiliki kestabilan statis jika tiga atau lebih kakinya ada di tanah. [2]

Kecerdasan buatan merupakan salah satu bagian dari ilmu komputer yang 
mempelajari bagaimana membuat mesin (komputer) dapat melakukan pekerjaan seperti dan sebaik yang dilakukan oleh manusia bahkan bisa lebih baik daripada yang dilakukan manusia. [3]

Dalam penerapannya, pengendali FuzzyLogic memanfaatkan pengalaman seorang pakar yang oleh perancang pengendali diekstrak ke dalam bentuk aturan-aturan if-then (jika-maka). Oleh karena itu, proses pengendalian akan mengikuti pendekatan secara linguistik. Pendekatan secara linguistik berupa interpretasi manusia (operator atau ahli) tentang tingkat keadaan suatu sistem, yang merupakan informasi penting dalam menggambarkan perilaku sistem dan jauh lebih mudah untuk diperoleh. Pengendali FuzzyLogic tidak memiliki ketergantungan pada variabel-variabel proses kendali sehingga pengendali ini banyak digunakan pada sistem yang memiliki sifat tidak linear dan perilaku dinamik yang berubah terhadap waktu. Namun dasar-dasar pengetahuan tentang sistem yang akan dikendalikan akan sangat membantu dalam memperoleh prestasi pengendalian yang memadai. [4]

Pada penelitian ini akan di terapkan Fuzzy Logic pada Behavior Based Control untuk kecerdasan Robot Quadpod. Fuzzy Logic PertamaPada Behavior Based Control akan menentukan posisi robot dan Fuzzy Logic Kedua akan menentukan Gerakan Robot.

\section{Metode Penelitian}

Diagram alir metodologi penelitian ditunjukkan dalam gambar berikut.

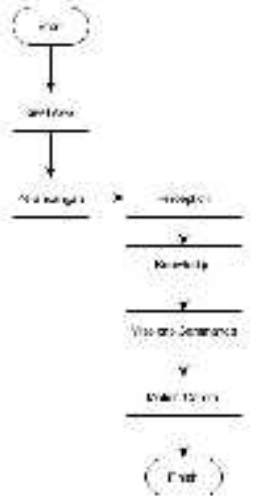

Gambar 1.Metodologi Penelitian
Dalam pertama kali melakukan penelitian adalah Riset awal. Riset awal terdiri dari pengumpulan Data dan Referensi yang berkaitan. Setelah semuaterkumpul, dilanjutkan dengan penilitian berupa Sensor Jarak. Data yang diterima Sensor Jarak dalam bentuk satuan jarak $(\mathrm{Cm})$. Jarak yang didapat juga tidak boleh melebihi kapasitas kemampuan minimal dan maksimum pada Sensor Jarak agar tidak terjadi kesalahan pengambilan data. Setelah pengambilan data selesai, data kemudian diproses menggunakan Kendali Cerdas Fuzzy Logic. Hasildari Fuzzy Logicberupa posisi.

\section{Pembahasan}

3.1 Blok Diagram Sistem Robot

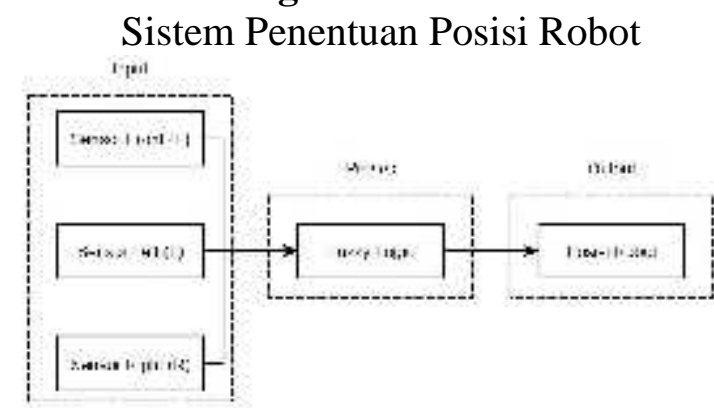

Gambar 2.Diagram Sistem Penentuan Posisi Robot

Robot ini memiliki 3 Input yang diperoleh dari 3 sensor yaitu Sensor Front (F), sensor Left (L) dan sensor Right (R). Input dari 3 sensor ini kemudian diproses menggunakan Fuzzy Logic yang akan menghasilkan Output berupa posisi robot.Kendali cerdas pada robot ini menggunakan kendali cerdas Fuzzy Logic menggunakan metode Mamdani. Kendali cerdas ini disimulasikan melalui aplikasi Mathlab.Proses pertama adalah pengambilan data menggunakan sensor. Setelah pengambilan data selesai, ketiga data tersebut kemudian disimpan kedalam variabel $\mathrm{F}, \mathrm{R}$ dan $\mathrm{L}$.

Untuk menentukan kemiringan / gradien disetiap subset dapat menggunakan rumus garis miring atau gradien yaitu :

$$
m=\frac{y_{1}-y_{2}}{x_{1}-x_{2}}
$$

Dengan rentang nilai Input pada fuzzy (sumbu x) dari 5-30 (Low \& High) 
dan titik tengah $(\mathrm{Med})$ dengan nilai 17.5 dan ketinggian (sumbu y) yaitu 1, dengan titik tengah memiliki nilai 17.5 dan rentang lebar Subset Med adalah 20 di setiap sisi kiri dan kanan memiliki lebar 10 maka jika dimasukkan kedalam rumus gradien seperti berikut :

$$
m=\frac{0-1}{10-1}=-0,1
$$

Maka kemiringan yang akan dibangun pada Fuzzy Subset adalah -0,1 yang ditunjukkan pada gambar berikut :

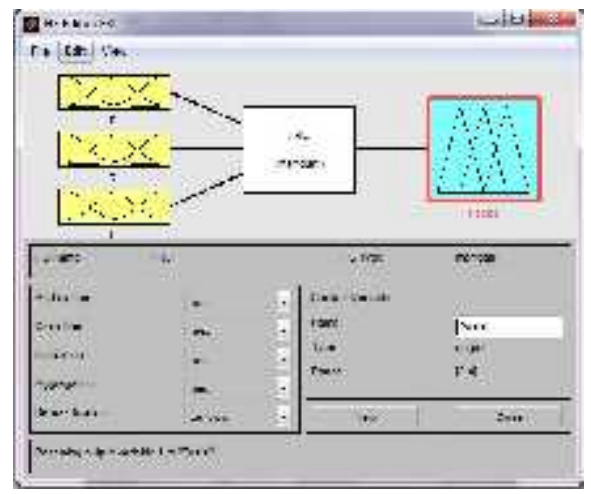

Gambar 3.Proses F \&R \& L

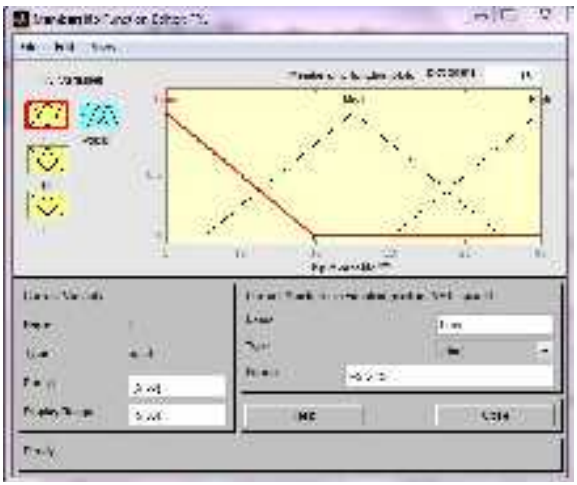

Gambar 4.Input Dari F

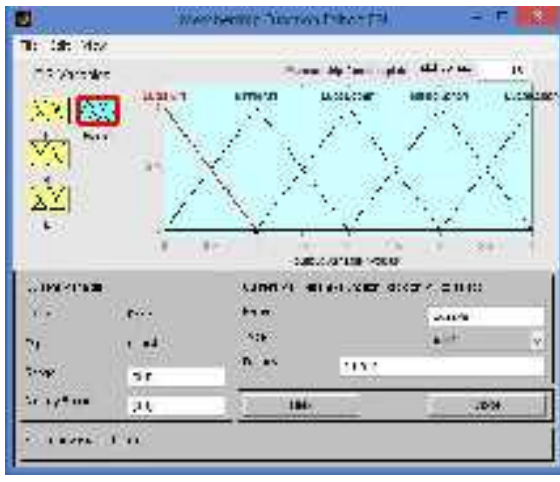

Gambar 5.Output Dari FRL

$\mathrm{F}, \mathrm{R}$ dan $\mathrm{L}$ memiliki rentang nilai dari 5 sampai 30, memiliki 3 Membership
Function yaituLow, Med, dan High. Output memiliki rentang nilai dari 0 sampai 4 yang terdiri dari 5Membership Function yaitu Belok Kanan, Serong Kanan, Maju, Serong Kiri dan Belok Kiri dan memiliki 27 Rule.Dalam kendali cerdas Fuzzy Logic ini memiliki 3 Input yaitu F, R dan L. Masing - masing dibangun dengan Fuzzy Set yang memiliki 3 Linguistic Value yaitu Low, Med dan High. Maka jumlah Rule Base yang harus dibangun dengan menggunakan persamaan 1 adalah:

$$
\mathrm{n}_{\text {Rules }}=(3)^{3}=27
$$

Maka Rule Base yang harus dibangun adalah 27 Rule.

Tabel 1.Rule F \& R \& L

\begin{tabular}{|c|c|c|c|c|}
\hline No & $\mathbf{F}$ & $\mathbf{R}$ & $\mathbf{L}$ & Act \\
\hline 1 & Low & Low & Med & Luas Kiri \\
\hline 2 & Low & Low & High & Luas Kiri \\
\hline 3 & Low & Med & High & Luas Kiri \\
\hline 4 & Med & Low & Med & $\begin{array}{c}\text { Miring } \\
\text { Kanan }\end{array}$ \\
\hline 5 & Med & Low & High & $\begin{array}{c}\text { Miring } \\
\text { Kanan }\end{array}$ \\
\hline 6 & High & Low & Med & $\begin{array}{c}\text { Miring } \\
\text { Kanan }\end{array}$ \\
\hline 7 & High & Low & High & $\begin{array}{c}\text { Miring } \\
\text { Kanan }\end{array}$ \\
\hline 8 & Med & Low & Low & Luas Depan \\
\hline 9 & Med & Med & Med & Luas Depan \\
\hline 10 & Med & Med & High & Luas Depan \\
\hline 11 & Med & High & Med & Luas Depan \\
\hline 12 & Med & High & High & Luas Depan \\
\hline 13 & High & Low & Low & Luas Depan \\
\hline 14 & High & Med & Med & Luas Depan \\
\hline 15 & High & Med & High & Luas Depan \\
\hline 16 & High & High & Med & Luas Depan \\
\hline 17 & High & High & High & Luas Depan \\
\hline 18 & Med & Med & Low & Miring Kiri \\
\hline 19 & Med & High & Low & Miring Kiri \\
\hline 20 & High & Med & Low & Miring Kiri \\
\hline 21 & High & High & Low & Miring Kiri \\
\hline 22 & Low & Low & Low & Luas Kanan \\
\hline 23 & Low & Med & Low & Luas Kanan \\
\hline 24 & Low & High & Low & Luas Kanan \\
\hline 25 & Low & Med & Med & Luas Kanan \\
\hline 26 & Low & High & Med & Luas Kanan \\
\hline 27 & Low & High & High & Luas Kanan \\
\hline
\end{tabular}


Setelah proses FRL selesai, Output yang didapat berupa posisi robot.

\subsection{Pengujian Fuzzy Logic}

Pengujian Fuzzy Logic dilakukan secara simulasi melalui Mathlab. Nilai input sebagai parameter pengganti $\mathrm{F}, \mathrm{R}$ dan $\mathrm{L}$ ditentukan sesuai prediksi kemungkinan yang akan terjadi yang nantinya akan menghasilkan keputasan Posisi robot.

\subsubsection{Posisi Luas Depan}

Pada Tabel 1,Untuk mendapatkan gerakan maju maka data prediksi yang akan digunakan adalah $\mathrm{F}=29, \mathrm{R}=24$ dan $\mathrm{L}=$ 25. Rule yang digunakan adalah Rule ke 17 Data ini telah di uji coba melalui Mathlab dan hasil akhirnya adalah 2 , pada gambar 10 menunjukkan bahwa posisi 2 mengarah pada posisi luas depan sesuai dengan Rule yang sudah ditentukan. Jika dilakukan perhitungan secara matematis maka persamaan yang digunakan adalah persamaan Triangular Membership Function. Data yang dimiliki adalah $\mathrm{F}=29$, $\mathrm{R}=24$ dan $\mathrm{L}=25$. Rule yang digunakan adalah Rule ke 17 yaitu :

Tahap pertama yaitu membangun Fuzzy Subset dengan data F menggunakan Rule High sesuai dengan Tabel 2. Nilai a, b dan $\mathrm{c}$ adalah $\mathrm{a}=20, \mathrm{~b}=30$ dan $\mathrm{c}=30$. Maka persamaan yang digunakan adalah:

$$
\mu(x, a, b, c)=\frac{x-a}{b-a} a \leq x \leq b
$$

jika semua data $\mathrm{F}$ dimasukkan maka akan menjadi :

$$
\begin{aligned}
& \mu(29,20,30,30)=\frac{29-20}{30-20} a \leq x \leq b \\
& \text { maka hasilnya adalah : } \\
& \mu F=0.9 \\
& \text { Kemudian membangun Fuzzy }
\end{aligned}
$$
Subset dengan data $\mathrm{R}$ menggunakan Rule High sesuai dengan Tabel 1. Jika data $\mathrm{R}$ dimasukkan maka akan menjadi :

$$
\begin{gathered}
\mu(24,20,30,30)=\frac{24-20}{30-20} a \leq x \leq b \\
\text { maka hasilnya adalah : } \\
\mu R=0.4
\end{gathered}
$$

Kemudian membangun Fuzzy Subset dengan data L menggunakan Rule High sesuai dengan Tabel 1. Jika data L dimasukkan maka akan menjadi :

$$
\begin{gathered}
\mu(25,20,30,30)=\frac{25-20}{30-20} a \leq x \leq b \\
\text { maka hasilnya adalah : } \\
\mu L=0.5
\end{gathered}
$$

Setelah Fuzzy Subset $\mu F, \mu L, \mu R$ selesai dibangun, kemudian hasil dari Fuzzy Subset dibangun kedalam Grafik 2D. Berikut grafik 2D dari setiap Fuzzy Subset:

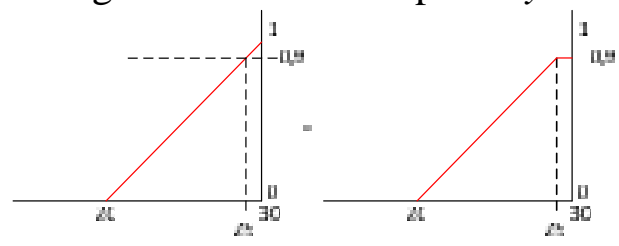

Gambar 8.Grafik Fuzzy Subset F

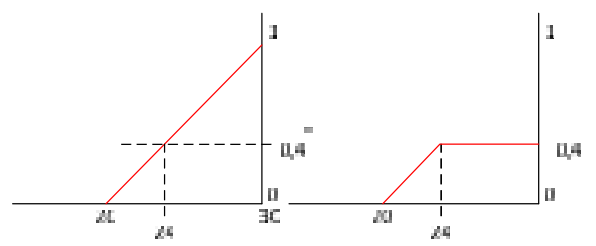

Gambar 9. Grafik Fuzzy Subset R

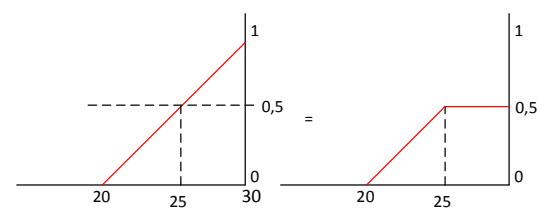

Gambar 10.Grafik Fuzzy Subset L

Setelah melakukan Fuzzy Subset, selanjutnya adalah melakukan Inferensi (Penalaran). Inferensi menggunakan Operator Implikasi Min atau nilai terkecil dari seluruh Input dalam satu Rule. Berikut adalah hasil dari Inferensi F,R dan L dalam satu Rule.

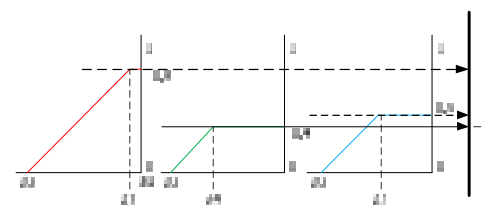

Gambar 11.Hasil Inferensi dari F,R dan L dalam satu Rule

Tahap Selanjutnya adalah Agregasi Output. Tahap ini menggunakan Agregasi dengan Operator Max atau tertinggi. Agregasi dilakukan jika menggunakan lebih dari 1 Rule, tetapi dalam percobaan 
ini hanya menggunakan 1 Rule jadi nilai yang digunakan adalah 0,4 hasil dari Inferensi. setelah tahap Agregasi selesai, maka selanjutnya adalah tahap Defuzzifikasi menggunakan metode Centroid.

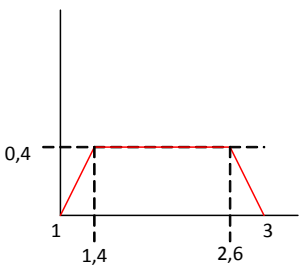

Gambar 12.Hasil Agregasi
Hasil Defuzzification dari gambar 12menggunakan persamaan dapat diperoleh :

$$
\begin{gathered}
\mathrm{X}_{\mathrm{c}}=\frac{1 * 0+1,4 * 0,4+2,6 * 0,4+(3 * 0)}{0+0,4+0,4+0} \\
=\frac{0,56+1,04}{0,8} \\
=2
\end{gathered}
$$

Jadi hasil Defuzzification adalah 2, maka hasil Defuzzification dinyatakan benar sesuai dengan uji coba Mathlab pada simulasi proses Luas Depan.

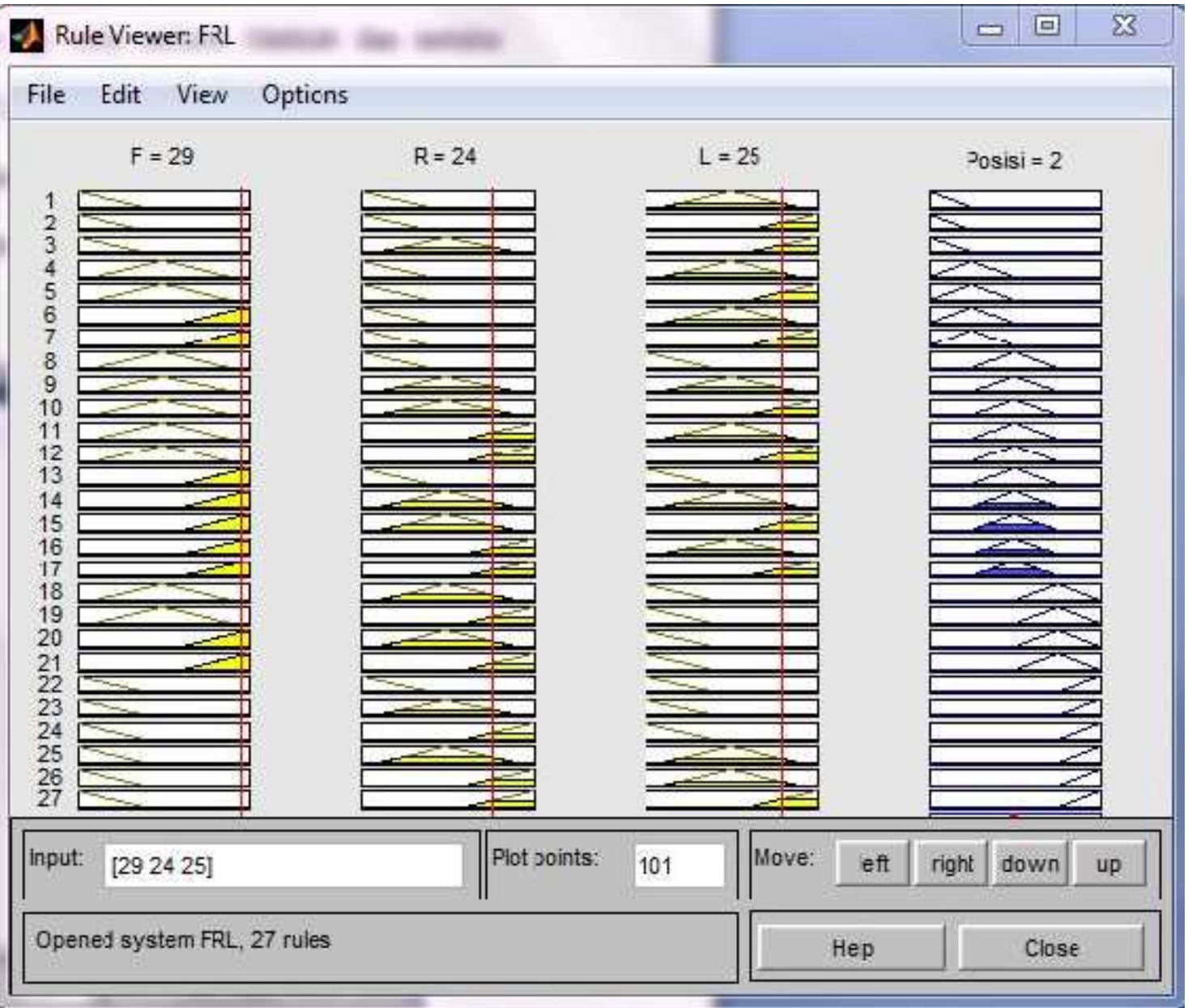

Gambar 13.Pembuktian Posisi Luas Depan Pada Mathlab

2. Pengujian dilakukan diseluruh

Pengujian BBC dilakukan secara simulasi melalui Mathlab. Nilai input / Stimulus sebagai ditentukan melalui Outputi Fuzzy Logic berupa posisi robot.

\section{$4 \quad$ Kesimpulan dan Saran} ini adalah :

Kesimpulan pada hasil penelitian

1. Data F, R dan L dibangkitkan secara Random.
Basic gerakan robot menggunakan simulasi Mathlab. Pada posisi luas depan, data Random yang digunakan adalah $\mathrm{F}=29, \mathrm{R}=24$ dan $\mathrm{L}=25$.

3. Hasil dari Mathlab kemudian dibuktikan menggunakan proses secara matematis dan hasil yang didapat pada Mathlab dan proses 
matematis adalah 2, dimana nilai 2 termasuk kedalam posisi luas depan. Pada posisi luas Kiri, data Random yang digunakan adalah $\mathrm{F}=7, \mathrm{R}=$ 5 dan $\mathrm{L}=22$. Data ini telah di uji coba melalui Mathlab dan hasil akhirnya adalah 0.369 , dimana nilai 0.369 adalah posisi luas Kiri. Pada posisi luas kanan, data Random yang digunakan adalah $\mathrm{F}=5, \mathrm{R}=$ 28 dan $\mathrm{L}=22$. Data ini telah di uji coba melalui Mathlab dan hasil akhirnya adalah 3.63 , dimana nilai 3.63 adalah posisi luas Kanan. Pada posisi miring kiri, data Random yang digunakan adalah $\mathrm{F}=14, \mathrm{R}=$ 8 dan $\mathrm{L}=23$. Data ini telah di uji coba melalui Mathlab dan hasil akhirnya adalah 1.24 , dimana nilai 1.24 adalah posisi miring Kiri. Pada posisi miring kanan, data Random yang digunakan adalah $\mathrm{F}=11, \mathrm{R}=$ 26 dan $\mathrm{L}=7$. Data ini telah di uji coba melalui Mathlab dan hasil akhirnya adalah 3.12 , dimana nilai 3.12 adalah posisi miring Kanan.

Setelah menyelesaikan penelitian ini maka terdapat beberapa hal yang dapat dijadikan sebagai saran untuk tindak lanjut hasil penelitian dimaksud, antara lain :

1. Hasil penelitian ini dapat dilanjutkan dalam bentuk penerapan langsung ke robot atau mengembangkan lagi dari sisi Fuzzy Logic atau mengembangkan Behavior Based Control

2. Untuk meningkatkan kemampuan deteksi robot maka perlu adanya ditambahkan sensor lagi agar dapat menentukan kondisi posisi robot lebih akurat

\section{$5 \quad$ Daftar Pustaka}

[1] Brookshear, J. Gleen, (2003). Computer Science: Suatu Pengantar, Marquette University

[2] Wicaksono, H. (2008). Perancangan Sistem Navigasi Otonom pada Behavior Based Hexapod Robot: Vol. 8, No. 2, 1

[3] Dahria, M. (2008). Kecerdasan Buatan (Artificial Intelligent) : Vol. 5, No. 2,1

[4] Yazid, E. (2009). Penerapan Kendali Cerdas pada Sistem Tangki Air menggunakan Fuzzy Logic : Vol. 9, No. 2, 2 